\title{
En mann i 40-årene med smerter i høyre lår og kne
}

\author{
Smerter i lår og kne som oppstår spontant, kan ha mange årsaker. \\ Vi beskriver her en tilstand som kan diagnostiseres ved hjelp av \\ MR-unders økelse, og som det er viktig å kjenne til.
}

En mann ble henvist fra fastlege til ortopedisk poliklinikk for belastningssmerter høyre lår og kne. Smertene hadde oppstått spontant over natten og var så sterke at han ikke kunne belaste høyre ben uten krykker. Han brukte medikamenter mot hypertensjon og gastroøsofageal refluks, men var ellers frisk. Han hadde ikke vært spesielt fysisk aktiv før det aktuelle. Henvisende lege hadde rekvirert MR-undersøkelse av høyre kne som viste normalt funn.

Smerte i lår og kne kan skrive seg fra hofteregionen. Det er derfor viktig at også hoften undersøkes.

To måneder etter symptomdebut ble han vurdert av ortoped som ikke fant noe galt $i$ kneet, men ortopeden noterte redusert bevegelighet i høyre hofteledd og rekvirerte skjelettrøntgen og MR-undersøkelse av bekken og hofte.

Røntgen viste en liten ujevnhet lateralt $i$ høyre caput femoris av usikker betydning. MR-bildene viste på høyre side et diffust benmargsødem i caput og collum femoris (fig 1). Etter kontrast var det opptak i samme område og ubetydelig væske i leddet. Det var ingen tegn til subkondral fraktur.

Pasienten ble deretter henvist til revmatologisk avdeling hvor han ble undersøkt én uke senere. Han hadde ikke hatt tegn til diaré, infeksjon eller flåttbitt før symptomene startet.

Mot smertene hadde han forsøkt paracetamol og NSAID-preparater med kun moderat effekt. Han var helt smertefri $i$ hvile, men ved belastning anga han 8 på en 0-10 numerisk smerteskala. Pasienten hadde et lavt alkoholforbruk og røykte ikke.

Ved klinisk undersøkelse var han afebril og i god allmenntilstand. Han hadde en haltende gange, og passiv fleksjon og innadrotasjon i høyre hofteledd var redusert på grunn av smerte. Organstatus, inkludert hud, negler og øvrige ledd, var upåfallende. Ved ultralyd av høyre hofteledd ble det notert ubetydelig økt væske i leddet, men ikke fortykket synovialhinne. Bentetthet målt med dobbelt radioabsorpsjonsmetri (dual X-ray absorptiometri, DXAl var redusert $i$ begge hofter med T-skår henholdsvis -2,7 på høyre side og -2,2 på venstre side. Ut fra pasientens alder tilsvarer dette henholdsvis $65 \%$ og $72 \%$ av forventet verdi. T-skår lavere enn $-2,5$ regnes som osteoporose.

Omfattende laboratorieutredning, inkludert bl.a. SR, CRP, Hb, blodtelling, lever-og nyrefunksjon, var upåfallende bortsett fra lett forhøyet parathyreoideahormon 8,5 pmol/l $(1,5-7,6)$. Ionisert kalsium var normal 1,21 mmol/l (1,18-1,32) og 25-OH-vitamin $D$ total $45 \mathrm{nmol} / \mathrm{l}(37-131)$.

Endokrinolog mente at det kunne foreligge en lett sekundær hyperparatyroidisme og anbefalte tilskudd av kalsium og vitamin D. Parathyroideascintigrafi viste ikke tegn til adenom.

På MR-bilder er benmargsødem karakterisert av diffust utbredte forandringer $\mathrm{i}$ form av væskelignende signal fra benmarg med nedsatt signalintensitet på T1-vektede bilder og økt signalintensitet på væskesensitive sekvenser, f.eks. T2-vektede bilder med fettsuppresjon eller «short tau inversion recovery»sekvens (STIR) (1).

Benmargsødem kan også påvises med skjelettscintigrafi (2), men da scintigrafi ikke antas å gi mer informasjon enn MRundersøkelse, ble dette ikke utført her. Benmargsødem er et uspesifikt funn, og man kan se det ved en rekke tilstander i skjelettet, både inflammatoriske, degenerative og traumatiske (3). Det var derfor mange aktuelle differensialdiagnoser hos denne pasienten.

I og med at symptomene hadde oppstått spontant, så vi bort fra traume eller gjentatte mikrotraumer som utløsende årsak (4). Benmargsødem kan være et tidlig funn ved begynnende artrose, men med intakt leddbrusk og fravær av osteofytter anså vi artrose som usannsynlig (5). Mer aktuelt var muligheten for en inflammatorisk revmatologisk sykdom. Artritt i hofteleddet skyldes ofte en spondylartrittilstand, enten i form av psoriasisartritt, reaktiv artritt eller ankyloserende spondylitt (tidligere Bekhterevs sykdom). Disse sykdommene kan ha svært varierende forløp, og CRP-nivået trenger ikke å være forhøyet. Det var imidlertid sparsomt med væske i leddet, og synovial-

\author{
Anne Julsrud Haugen \\ annhau@so-hf.no \\ Revmatologisk avdeling \\ Sykehuset Østfold \\ Haroon Ur Rashid \\ Revmatologisk avdeling \\ Sykehuset Østfold
}

\section{Eivind Hasvik}

Fysioterapiavdelingen Sykehuset Østfold

Jostein Gleditsch

Avdeling for bildediagnostikk Sykehuset Østfold

\section{Lars Grøvle}

Revmatologisk avdeling

Sykehuset Østfold 

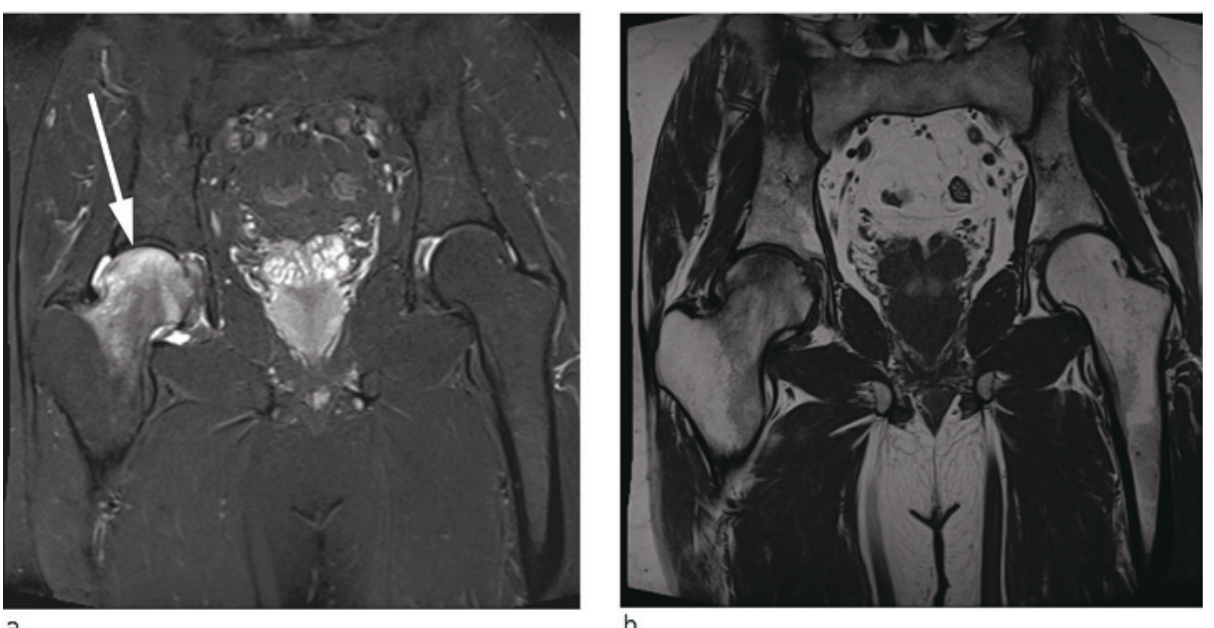

Figur 1 Diffust benmargsødem i høyre caput og collum femoris - a) STIR-sekvens, b) T1-sekvens
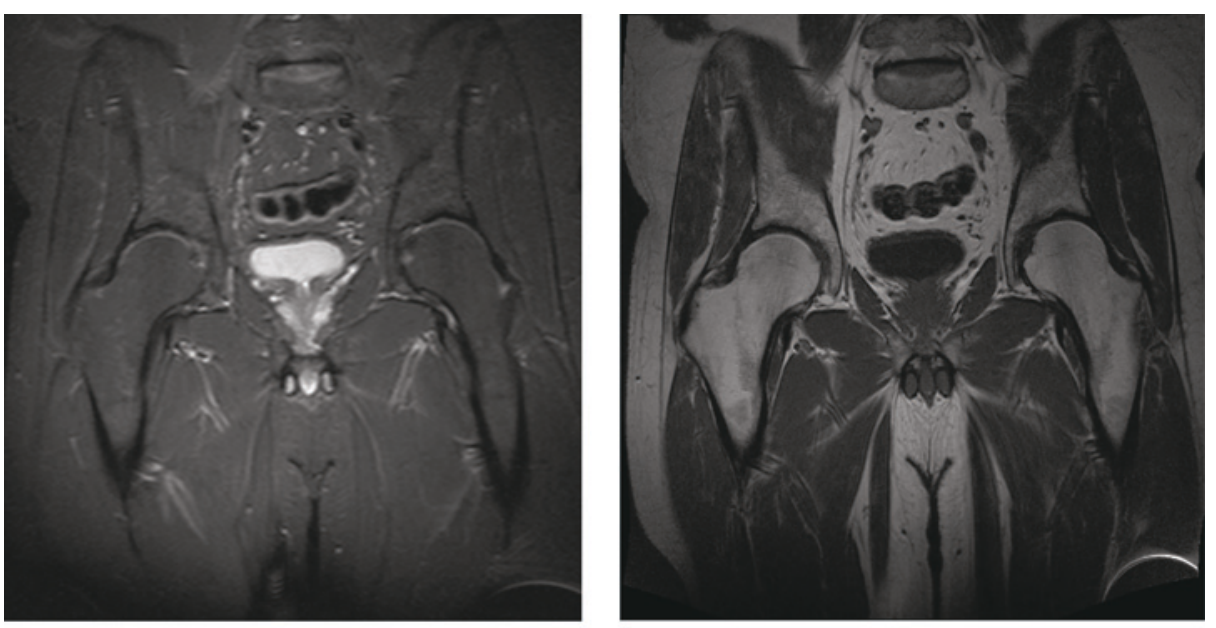

b ytterligere tre måneder var MR bekken og hofteledd helt normalisert (fig 2). Bentetthetsmåling viste da T-skår -2,6, og -2,1 i henholdsvis høyre og venstre hofte. Videre oppfølging av endokrinolog viste vedvarende lett forhøyet PTH-nivå uten at det ble funnet noen sikker årsak til dette.

\section{Diskusjon}

Tilstanden vi omtaler i denne kasuistikken, ble først beskrevet i 1959 som lokalisert osteoporose fordi skjelettrøntgen viste redusert mineralisering i hofteregionen (10). Da smerter og røntgenforandringer viste seg å være reversible, ble begrepet «transient osteoporosis of the hip» (TOH) introdusert. «Regional migratory osteoporosis» (RMO) har senere vært benyttet hvor tilstanden flytter seg fra ett ledd til et annet (11). Etter at MR-undersøkelser kom i bruk er dette blitt standardmetoden for å diagnostisere tilstanden. I ICD-10 kodes benmargsødemsyndrom som M 81.6 (lokalisert osteoporose/ Lequesnes sykdom). Lequesne beskrev ti pasienter med «transient osteoporosis of the hip» som han oppfattet som en variant av Südecks atrofi (12). I senere studier har man imidlertid ikke kunnet bekrefte sammenheng mellom benmargsødemsyndrom og Südecks atrofi (komplekst regionalt smertesyndrom) (13). På norsk har tilstanden så vidt vært omtalt som lokalisert osteoporose med benmargsødem, og som benmargsødem i forbigående osteoporose $(14,15)$.

Litteraturen om benmargsødemsyndrom utgjøres hovedsakelig av kasuistikker og små pasientserier, og man har liten kunnskap om etiologi eller patofysiologi (13). Epidemiologiske data finnes ikke. Tilstanden er særlig beskrevet hos menn i alderen 30-60 år, men er også sett blant gravide kvinner i siste trimester. Benmargsødemsyndrom synes hyppigst å affisere hofteregionen, men forekommer også i kne, ankel og fot, sjelden i overekstremitetene eller andre lokalisasjoner. I hoften ses forandringene oftest i proksimale femur, men de kan også forekomme i acetabulum. Spontan bedring uten sekvele ser ut til å være det vanligste, symptomene kan vare fra noen måneder opp til et par år, men residiv forekommer (16). I de tilfellene hvor det er utført benmineralmåling, har det vært påvist reduserte verdier i det affiserte området slik som hos vår pasient, det er også rapportert om brudd $(10,17)$. Kasuistikker tyder på at bentettheten kan normalisere seg uten spesifikk behandling (18). Det er kjent at avlastning av en ekstremitet i seg selv kan medføre redusert bentetthet, men neppe så mye som $\mathrm{i}$ dette tilfellet (19).

Ifølge flere kasuistikker og små ukontrollerte studier er pasienter med benmargsødemsyndrom blitt behandlet med osteopo-
(6). Andre mulige årsaker som labrumrift, iliopsoas bursitt, tendinose i hofteflektorer, full tilbakegang av benmargsødemet $i$ caput femoris, men noe ødem i acetabulum. Etter 
rosemidler, spesielt bisfosfonater $(9,20-23)$ Det finnes imidlertid ingen placebokontrollerte studier, og det er derfor ikke mulig å vite hvilken effekt bisfosfonater eventuelt kan ha på sykdomsforløpet ved tilstanden. Hos vår pasient startet vi med alendronat. Vi har senere hatt fire pasienter med benmargsødemsyndrom, den første av disse fikk også alendronat, de siste tre har vi ikke gitt bisfosfonater. Alle fem pasienter er blitt bedre. Det foreligger også rapporter om bruk av prostasyklinanaloger (24), hyperbar oksygenterapi (25) og trykkbølgebehandling (26), men per i dag finnes det ingen behandling hvor effekten er tilstrekkelig dokumentert til å kunne anbefales.

\section{Konklusjon}

Benmargsødemsyndrom er en aktuell differensialdiagnose hos pasienter med spontant oppståtte smerter i store ledd i underekstremitetene, særlig hofte. Det er en uavklart tilstand med et åpenbart behov for mer kunnskap. Vi deltar gjerne $i$ et samarbeid med andre interesserte om dette.

Pasienten har gitt samtykke til at artikkelen blir publisert.

\section{Anne Julsrud Haugen (f. 1959)}

er overlege og ph.d.

Forfatter har fylt ut ICMJE-skjemaet og oppgir ingen interessekonflikter.

\section{Haroon Ur Rashid (f. 1968)}

er spesialist i revmatologi.

Forfatter har fylt ut ICMJE-skjemaet og oppgir ingen interessekonflikter.

\section{Eivind Hasvik (f. 1979)}

er fysioterapeut, m.sc. og ph.d.-kandidat. Forfatter har fylt ut ICMJE-skjemaet og oppgir ingen interessekonflikter.

\section{Jostein Gleditsch (f. 1971)}

er seksjonsoverlege.

Forfatter har fylt ut ICMJE-skjemaet og oppgir ingen interessekonflikter.

\section{Lars Grøvle (f. 1957)}

er overlege og dr.philos.

Forfatter har fylt ut ICMJE-skjemaet og oppgir ingen interessekonflikter.

\section{Litteratur}

1. Mirowitz SA, Apicella P. Reinus WR et al. MR imaging of bone marrow lesions: relative conspicuousness on T1-weighted, fat-suppressed T2weighted, and STIR images. AJR Am J Roentgenol 1994; 162: 215-21.

2. Bray ST, Partain CL, Teates CD et al The value of the bone scan in idiopathic regional migratory osteoporosis. J Nucl Med 1979; 20: 1268-71.

3. Eriksen EF, Ringe JD. Bone marrow lesions: a universal bone response to injury? Rheumatol Int 2012: 32: 575-84.

4. Mandalia V, Fogg AJ, Chari R et al. Bone bruising of the knee. Clin Radiol 2005; 60: 627-36

5. Barr AJ, Campbell TM, Hopkinson D et al. A systematic review of the relationship between subchondral bone features, pain and structural pathology in peripheral joint osteoarthritis. Arthritis Res Ther 2015; 17: 228 .

6. Karantanas AH. Acute bone marrow edema of the hip: role of MR imaging. Eur Radiol 2007: 17: 2225-36.

7. Margo K, Drezner J, Motzkin D. Evaluation and management of hip pain: an algorithmic approach J Fam Pract 2003: 52: 607-17.

8. Patel S. Primary bone marrow oedema syndromes. Rheumatology (Oxford) 2014; 53: 785-92.

9. Emad Y, Ragab Y, El-Shaarawy N et al. Transient osteoporosis of the hip, complete resolution after treatment with alendronate as observed by MRI description of eight cases and review of the literature. Clin Rheumatol 2012; 31: 1641-7

10. Curtiss PH Jr, Kincaid WE. Transitory demineralization of the hip in pregnancy. A report of three cases. J Bone Joint Surg Am 1959: 41-A: 1327-33.

11. Toms AP, Marshall TJ, Becker E et al. Regional migratory osteoporosis: a review illustrated by five cases. Clin Radiol 2005; 60: 425-38.

12. Lequesne M. Transient osteoporosis of the hip. A nontraumatic variety of Südeck's atrophy. Ann Rheum Dis 1968; 27: 463-71.

13. Thiryayi WA, Thiryayi SA, Freemont AJ. Histopathological perspective on bone marrow oedema, reactive bone change and haemorrhage. Eur J Radiol 2008; 67: $62-7$

14. Syversen U, Halse JI. Bisfosfonatbehandling av osteoporose og andre skjelettsykdommer. Tidssk Nor Legeforen 2011; 131: 244-7.

15. Stiris MG. Magnetisk resonanstomografi ved skjelett- og bløtdelstraumer. Tidsskr Nor Lægeforen 2000; 120: 1060-6.

16. Lakhanpal S, Ginsburg WW, Luthra HS et al. Transient regional osteoporosis. A study of 56 cases and review of the literature. Ann Intern Med 1987; 106: $444-50$

17. Trevisan C, Ortolani S. Bone loss and recovery in regional migratory osteoporosis. Osteoporos Int 2002: 13: $901-6$

18. Niimi R, Sudo A, Hasegawa $M$ et al. Changes in bone mineral density in transient osteoporosis of the hip. J Bone Joint Surg Br 2006; 88: 1438-40.

19. Lau RY, Guo X. A review on current osteoporosis research: with special focus on disuse bone loss. J Osteoporos 2011; 2011: 293808. E-publisert 16. august 2011

20. Varenna M, Zucchi F, Binelli L et al. Intravenous pamidronate in the treatment of transient osteoporosis of the hip. Bone 2002; 31: 96-101.

21. Ringe JD, Dorst A, Faber H. Effective and rapid treatment of painful localized transient osteoporosis (bone marrow edema) with intravenous ibandronate. Osteoporos Int 2005: 16: 2063-8.
22. Seok H, Kim YT, Kim SH et al. Treatment of transient osteoporosis of the hip with intravenous zoledronate - a case report - Ann Rehabil Med 2011. 35: $432-5$.

23. Fabbriciani G, Pirro M, Manfredelli MR et al. Transient osteoporosis of the hip: successful treatment with teriparatide. Rheumatol Int 2012; 32: 1367-70.

24. Meizer R, Radda C, Stolz G et al. MRI-controlled analysis of 104 patients with painful bone marrow edema in different joint localizations treated with the prostacyclin analogue iloprost. Wien Klin Wochenschr 2005; 117: 278-86.

25. Capone A, Podda D, Ennas F et al. Hyperbaric oxygen therapy for transient bone marrow oedema syndrome of the hip. Hip Int 2011; 21: 211-6.

26. d'Agostino C, Romeo P, Lavanga V et al. Effectiveness of extracorporeal shock wave therapy in bone marrow edema syndrome of the hip. Rheumatol Int 2014; 34: 1513-8.

Mottatt 29.10. 2015, første revisjon innsendt 3.3. 2016, godkjent 28.6. 2016. Redaktør: Liv-Ellen Vangsnes. 